\title{
Long Survival in Patient with Unrepaired Tetralogy of Fallot and Down Syndrome
}

\author{
Júlio César Queiroz França', Reinaldo Bulgarelli Bestetti ${ }^{2}$, Augusto Cardinalli Neto ${ }^{1}$, Jamil Alli Murad Junior ${ }^{1}$, \\ Gabriela Santos Longo ${ }^{1}$, Edson Rodrigo Andreta Sinhorini ${ }^{1}$ \\ Faculdade de Medicina de São José do Rio Preto - FAMERP'; Universidade de Ribeirão Preto - UNAERP², São José do Rio Preto, SP - Brazil
}

\section{Introduction}

Tetralogy of Fallot (TF) is the most prevalent cyanotic congenital heart disease in childhood and accounts for about $10 \%$ of the cases of congenital heart disease in the United States. ${ }^{1}$ In patients with Down syndrome (DS), congenital heart disease occurs in about $50 \%$ of the cases. TF is one of several defects of patients with Down syndrome and it may occur from $0-15.5 \%$ in different series. ${ }^{1,2}$ Pathophysiology is essentially dependent on the severity of obstruction of the right ventricle outflow tract (RVOT) leading to right-to-left shunt. The right-to-left shunt degree is dependent on systemic vascular resistance (SVR), as the RVOT obstruction is usually fixed. Decrease in SVR increases right-to-left shunt. ${ }^{2,3}$ Given the high prevalence of congenital heart defects, echocardiography should be considered in patients with DS. ${ }^{4}$ Definitive surgical repair of TF is recommended after the first month of life, as long as clinical conditions are favorable.

\section{Case Report}

JHB patient, 51 years old, male, was admitted to hospital after sudden onset of left face, arm, hand, leg and feet hemiparesis with conjugate eye deviation to the right and drowsiness. Diagnosis of ischemic stroke (IS) with involvement of the internal capsule was confirmed on computed tomography of the brain. On admission, the patient was out of thrombolysis time, so hospitalization and medical treatment was chosen.

While in hospital, the patient's condition got worse with progression of NIHSS from 13 to 17 . The patient also presented nosocomial pneumonia. After treatment with intravenous antibiotic therapy, motor and respiratory physiotherapy, the patient showed significant improvement.

\section{Keywords}

Heart Defects, Congenital. Tetralogy of Fallot; Down Syndrome; Stroke; Echocardiography/methods; Survivorship (Public Health).

\section{Mailing Address: Júlio César Queiroz de França •}

Rua Luis Figueiredo Filho, 525, apto. 43B, Condomínio Saint Exupery.

Postal Code 150841-80, Vila Nossa Senhora do Bonfim, São José do Rio Preto, SP - Brazil

E-mail: jucequdefr@hotmail.com

Manuscript received January 14, 2016; revised February 27, 2016; approved March 28, 2016.

DOI: $10.5935 / 2318-8219.20160025$
This patient with DS was diagnosed with TF five years before, but the family chose not to perform surgical correction of the heart disease at the time. There is no report of previous hospitalization in any other medical service and the patient's aunt and caregiver reports that, since birth, the patient has always been healthy and has never reported dyspnea. The patient walked without assistance, was able to dance in parties, performed basic activities of daily living without assistance (showered without assistance, ate, talked on the phone). The patient had developmental delay, started walking at five and talking at eight. Cardiac auscultation reveals systolic ejection murmur in crescendo-decrescendo, better audible in the mitral and tricuspid foci, and the presence of single second heart sound. Peripheral oxygen saturation always 92 - 94\% in ambient air.

Diagnosis of TF was confirmed with transthoracic echocardiography showing severe right ventricular hypertrophy (wall thickness of $14 \mathrm{~mm}$ ) and perimembranous ventricular septal defect (VSD) with diameter of $8 \mathrm{~mm}$ and turbulent flow on Doppler (Figure/Video 1), associated with right ventricular outflow tract obstruction (muscle edge) with an average gradient of $45 \mathrm{mmHg}$ (Figure/Video 2), as well as overriding aorta (Figure/Video 3).

\section{Discussion}

TF was originally described by Steno in 1673 , but it was the physician Etienne-Louis Fallot who emphasized and grouped the four main morphological cardiac abnormalities that characterize the disease: ventricular septal defect, aorta dextroposition (aorta overriding), pulmonary artery stenosis and right ventricular hypertrophy. ${ }^{1,4,5}$ All these defects result from anterior deviation of the infundibular septum during the division of the conal trunk into aorta and pulmonary artery, causing misalignment between the infundibular septum and the muscular ventricular septum. ${ }^{6}$ Other cyanotic congenital heart diseases that should be considered in the differential diagnosis of TF are double outlet right ventricle with pulmonary stenosis and atresia of the pulmonary valve with VSD and aortopulmonary collateral arteries. ${ }^{6,7}$

The longevity of this patient is certainly linked to the association between a major VSD and severe pulmonary stenosis, enough not to cause severe hypoxia, but satisfactory to protect the pulmonary vascular bed from the complications associated with CIV (increased pulmonary vascular resistance and pulmonary hypertension). Other mechanisms are cited to explain high survival in patients with TF: left ventricular hypertrophy that maintains a left-to-right gradient and patent ductus arteriosus allowing extra oxygenation of the blood reaching the right ventricle. ${ }^{7,8}$ 


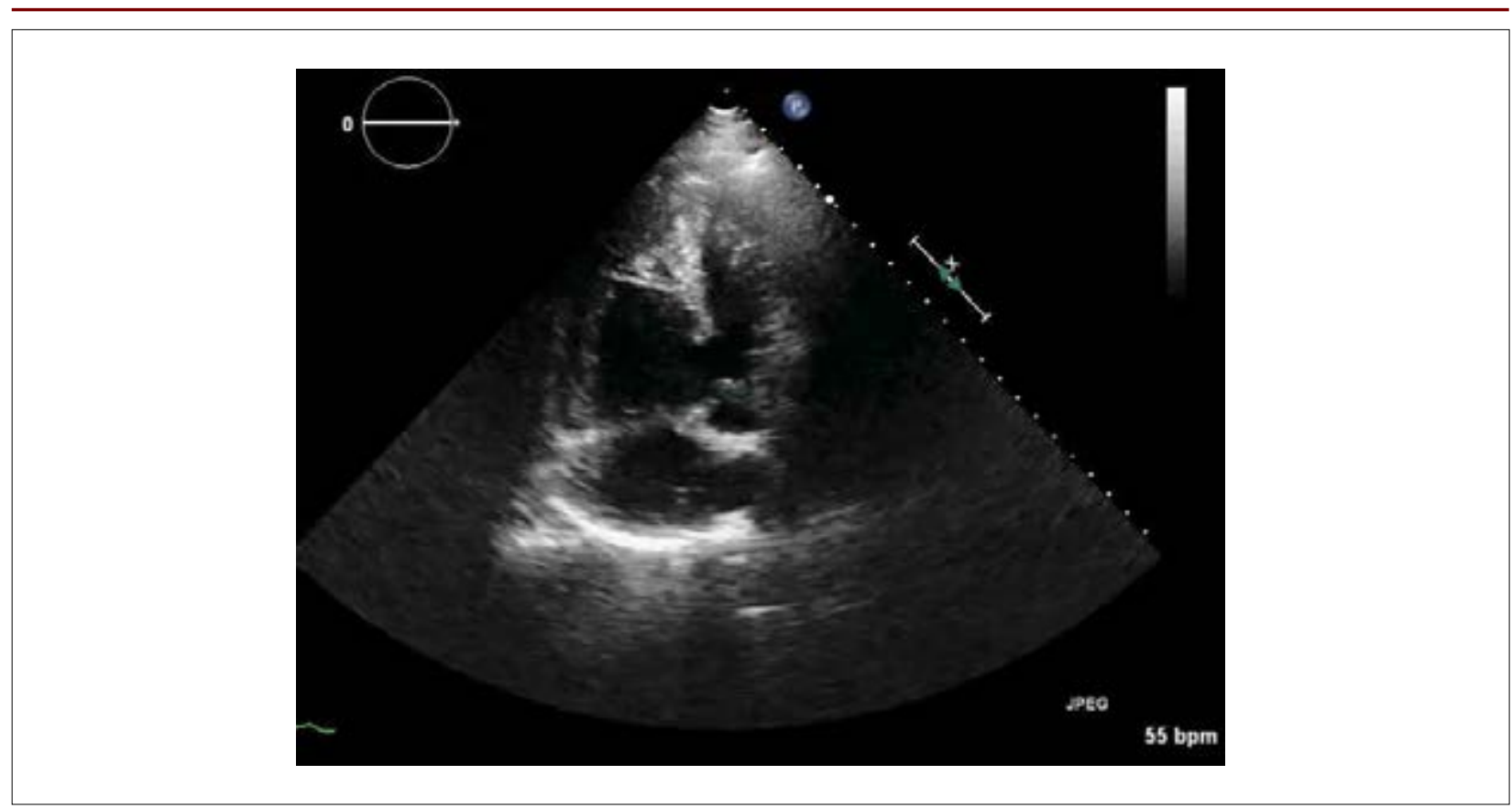

Video 1 - Right ventricular hypertrophy and ventricular septal defect.

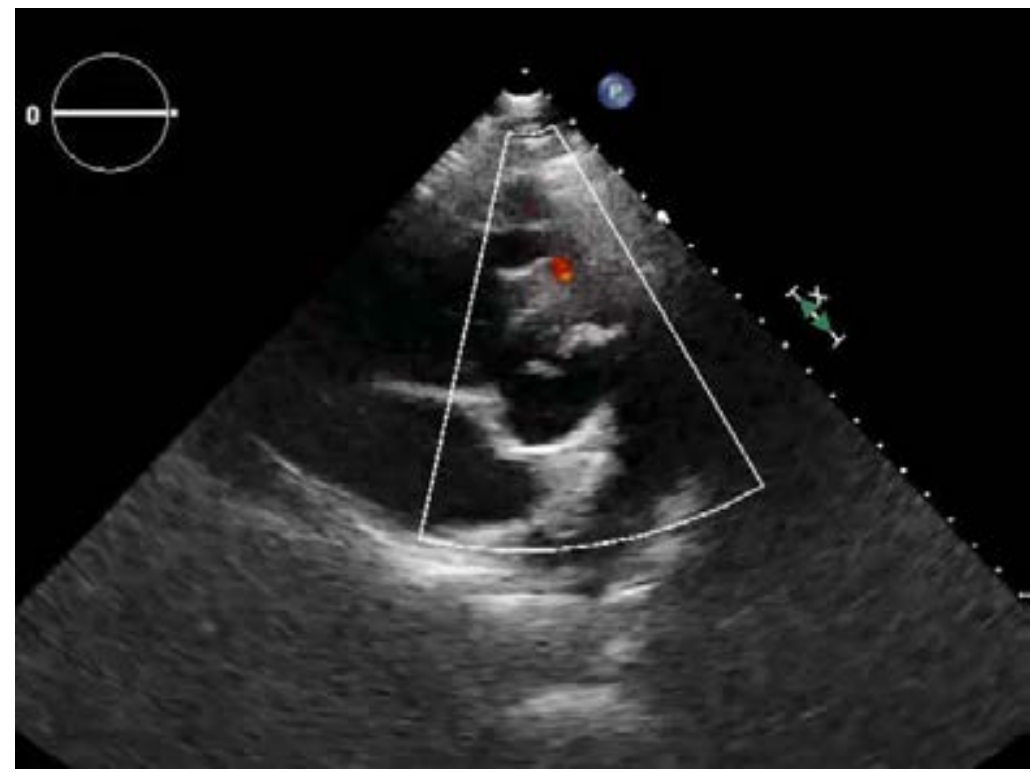

Video 2 - Right ventricular oufflow tract obstruction.

From a clinical perspective, TF can appear in three ways: if the stenosis is mild, the shunt is from the left to right and the patient is acyanotic (pink Fallot); if stenosis is moderate, the shunt is from the right to the left, the patient is cyanotic (classic Fallot); if the obstruction is extreme with pulmonary atresia, the entire volume of the systemic venous return is diverted to the left by the VSD and the pulmonary flow is dependent on the ductus arteriosus patency (extreme Fallot) or the existence of aortopulmonary collateral artery. ${ }^{4,8}$

The most common causes of death in non-operated patients include thromboembolic complications (stroke, PTE), malignant arrhythmias, pulmonary hemorrhage and endocarditis. ${ }^{4,8}$ The patient in question had cardioembolic stroke progressing during hospitalization, which worsened 


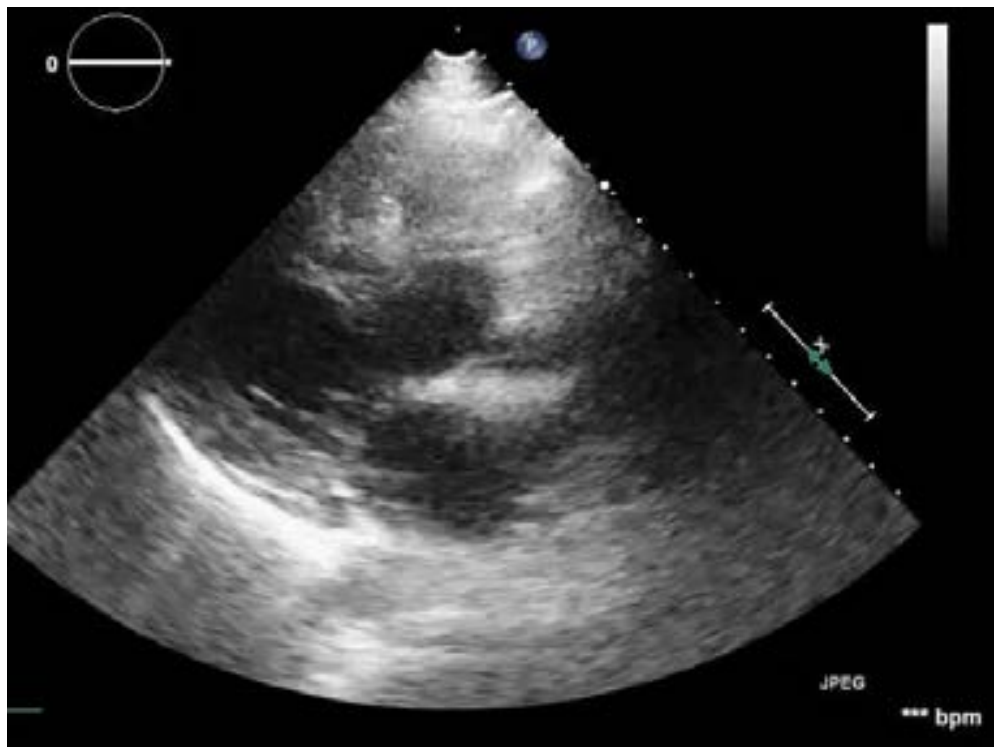

Video 3 - Overriding aorta.

due to aspiration pneumonia. However, the patient presents significant clinical improvement in use of cefepime and clindamycin with hospital discharge expected upon the end of the antibiotic course. Family members remain reluctant to corrective surgery despite the success reported in some TF correction work done in elderly patients. ${ }^{9}$

To prevent new embolic complications, full anticoagulation was started with warfarin and follow-up in specialized clinics for INR control. After extensive research conducted in Pubmed, we report the case with the highest longevity of unrepaired Tetralogy of Fallot and Down Syndrome ever described in the medical literature.

\section{Authors' contributions}

Research creation and design: França JCQ, Bestetti RB, Cardinalli Neto A, Longo GS; Data acquisition: França JCQ,

\section{References}

1. Yang X, Freeman LJ, Ross C. Unoperated tetralogy of Fallot: case report of a natural survivor who died in his 73rd year; is it ever too late to operate. Postgrad Med J. 2005;81(952):133-4.

2. Hoffman JI. Incidence of congenital heart disease: I. Postnatalincidence. Pediatr Cardiol 1995;16(3):103-13.

3. Fairley SL, Sands AJ, Wilson CM. Uncorrected tetralogy of Fallot: Adult presentation in the 61st year of life. Int J Cardiol. 200;128(1):9e-11e.

4. Chandrasekaran B, Wilde P, McCrea WA. Tetralogy of Fallot in a 78-year-old man. N Engl J Med. 2007;357(11):1160-1.

5. Pinsky WW, Arciniegas E. Tetralogy of Fallot. Pediatr Clin North Am. 1990;37(1):179-92.
Sinhorini ERA; Data analysis and interpretation: França JCQ, Bestetti RB, Murad Jr JA,; Manuscript drafting: França JCQ, Bestetti RB, Longo GS, Sinhorini ERA; Critical revision of the manuscript as for important intellectual content: França JCQ, Bestetti RB, Cardinalli Neto A, Murad Jr JA,.

\section{Potential Conflicts of Interest}

There are no relevant conflicts of interest.

\section{Sources of Funding}

This study had no external funding sources.

\section{Academic Association}

This study is not associated with any graduate program.

6. Chang AC, Hanley FL, Wernovsky G, Wessel DL - Pediatric cardiac intensive care .Baltimore(USA): Willians \& Wilkins;1998.p.107-11.

7. Santos W, Pereira S, Camacho A, Marques V, Matos P, Gomes V: Um caso raro de longevidade da tetralogia de Fallot. Rev Port Cardiol. 2009;28(4):473-7.

8. Van Arsdell GS, Maharaj GS, Tom J , Rao V, Coles JG, Freedom RM, et al. What is the optimalage for repair of tetralogy of Fallot? Circulation, 2000;102(19 Suppl 3):III-123-9.

9. Semeraro O, Scott B, Vermeersch P. Surgical correction of tetralogy of Fallot in a seventy-five year old patient. Int J Cardiol. 2008; 128(3):e98-100. 
